\title{
Influência do ácido indolbutírico no enraizamento de alecrim-pimenta (Lippia sidoides) em leito com umidade controlada
}

\author{
FIGUEIREDO, L.S. ${ }^{1^{*}}$; BONFIM, F.P.G. ${ }^{2}$; FERRAZ, E.O. ${ }^{2}$; CASTRO, C.E. ${ }^{2}$; SOUZA, M. F. ${ }^{2}$; MARTINS, E. R. ${ }^{2}$ \\ Universidade Estadual de Montes Claros, Campus Universitário Darcy Ribeiro, Centro de Ciências Biológicas e \\ da Saúde, Departamento de Biologia Geral, Vila Mauricéia, Montes Claros, MG CEP: 39401-089. \\ *lourdes.figueiredo@unimontes.br. ${ }^{2}$ Universidade Federal de Minas Gerais, Instituto de Ciências Agrárias da \\ UFMG Caixa Postal 135, Montes Claros, MG CEP: 39404-006
}

\begin{abstract}
RESUMO: Aespécie Lippia sidoides (Verbenaceae) é conhecida no Brasil como alecrim-pimenta, um arbusto típico da vegetação do nordeste brasileiro. Este trabalho foi realizado no Instituto de Ciências Agrárias da UFMG, em Montes Claros, Brasil, coma finalidade de estudar a propagação vegetativa do alecrim-pimenta em leito de enraizamento com umidade controlada. Estacas da planta foram submetidas às seguintes concentrações de ácido indolbutírico (IBA): 0, 250, 500, 750 e $1000 \mathrm{mg} \mathrm{L}^{-1}$ durante 24 horas. O experimento foi conduzido em delineamento inteiramente casualizado (DIC) com cinco repetições, sendo dez estacas por repetição. Após 45 dias de implantação foram avaliados o número de raízes, o número de brotações, o comprimento da maior raiz, o índice de enraizamento e a porcentagem de enraizamento. Observou-se que as variáveis comprimento de raiz, número de raízes e índice de enraizamento apresentaram diferenças significativas entre as diversas concentrações de IBA. No entanto, a porcentagem de enraizamento não foi afetada significativamente, provavelmente pelo controle da umidade relativa e pela manutenção das folhas das estacas.
\end{abstract}

Palavras-chave: plantas medicinais, propagação vegetativa, estaquia

\begin{abstract}
Influence of indolebutyric acid on "alecrim-pimenta" (Lippia sidoides) rooting bed under controlled humidity. The species Lippia sidoides Cham. (Verbenaceae) is known in Brazil as "alecrim-pimenta", a typical shrub from the Northeastern Brazil vegetation. This work was carried out in the Agronomical Sciences Institute from Minas Gerais State University (UFMG), Montes Claros, Minas Gerais State, Brazil, in order to study the vegetative propagation of this species in rooting bed under controlled humidity. Herbaceous cuttings were treated with the following concentrations of indolebutyric acid (IBA): 0, 250, 500, 750, and $1000 \mathrm{mg} \mathrm{L}^{-1}$ for 24 hours. The experimental design was completely randomized (CRD) with five replicates of 10 cuttings each. After 45 days, root and sprout numbers, the highest root length, and rooting index and percentage were evaluated. Root length and number and rooting index had significant differences among IBA concentrations. However, rooting percentage was not significantly affected, probably due to the control of relative humidity and the maintenance of cuttings from leaves.
\end{abstract}

Key words: medicinal plants, vegetative propagation, herbaceous cuttings

\section{INTRODUÇÃO}

O alecrim-pimenta - Lippia sidoides Cham (Verbenaceae) apresenta folhas com $4 \%$ de óleo essencial, contendo cerca de $60 \%$ de timol ou uma mistura de timol e carvacrol, além disso, dentre os componentes fixos, estão flavonóides e quinonas (Lorenzi \& Matos, 2002). Estes constituintes químicos conferem à espécie um alto valor medicinal, implicando em largo uso da planta pelas populações carentes. Mas, a produção da matéria prima é dificultada, pois são poucos os estudos sobre seu cultivo e métodos de propagação. $O$ enraizamento de estacas dessa espécie é uma alternativa de propagação comumente utilizada, uma vez que permite o início da produção em um

Recebido para publicação em 05/11/2007

Aceito para publicação em 06/08/2008

Rev. Bras. PI. Med., Botucatu, v.11, n.1, p.33-36, 2009. 
menor espaço de tempo e obtenção de plantas comcaracterísticas desejáveis a partir da seleção de matrizes. Para acelerar e promover o enraizamento das estacas, habitualmente são empregados reguladores de crescimento do grupo das auxinas, os quais levam à maior porcentagem de formação das raízes, melhor qualidade das mesmas e uniformidade no enraizamento (Ono \& Rodrigues 1996). O ácido indolbutírico (IBA) é considerado a auxina mais eficiente para essa finalidade, por sua atoxicidade, estabilidade à ação da luz, maior aderência à estaca e maior resistência ao ataque por ação biológica (Hartmann et al., 1990). Outro aspecto relevante refere-se às condições climáticas para propagação de estacas, devendo-se, às vezes, adotar práticas alternativas para controlar a umidade. Assim, o objetivo do presente trabalho foi estudar o efeito do IBA no enraizamento de alecrim-pimenta em leito de enraizamento comumidade controlada.

\section{MATERIAL E MÉTODO}

O trabalho foi desenvolvido no período de 15 de março a 30 de abril em leito de enraizamento com umidade controlada, no Núcleo de Ciências Agrárias da Universidade Federal de Minas Gerais, Campus Montes Claros - MG (NCA/UFMG). O delineamento experimental foi o inteiramente casualizado, com cinco tratamentos e cinco repetições, sendo a unidade experimental constituída por 10 estacas. Os tratamentos utilizados foram as concentrações: 0; 250; 500; 750 e $1000 \mathrm{mg} \mathrm{L}^{-1}$ de ácido indolbutírico (IBA). Utilizaram-se estacas de Lippia sidoides Cham. (Verbenaceae) coletadas no NCA/UFMG, na porção mediana de ramos de plantas-matrizes uniformes, sendo padronizadas com $10 \mathrm{~cm}$ de comprimento e dois pares de folhas. As estacas foram mantidas imersas nas soluções por 24 horas e colocadas no leito de enraizamento com umidade mantida entre 75 a $85 \%$, por meio de umidostato, em substrato comercial. Após 45 dias, avaliou-se 0 número de raízes, número de brotações, comprimento da maior raiz, índice de enraizamento e porcentagem de enraizamento. Os dados foram submetidos à análise de regressão e de correlações de Spearman. Os dados de número de raízes e número de brotações foram transformados para $\sqrt{x+0,5}$, e a porcentagem de enraizamento foi transformada para arco seno $x: 100$.

\section{RESULTADOE DISCUSSÃO}

$\mathrm{Na}$ Tabela 1, observa-se que apenas as variáveis comprimento de raiz (CRAIZ), número de raízes (NRAIZ) e índice de enraizamento (IR) apresentaram diferenças significativas entre as doses de IBA. Assim, equações quadráticas foram ajustadas (Figuras 1 e 2), sendo que as doses estimadas de IBA, que levaram ao valor máximo de cada variável, foram: 793 mg L-1 (NRAIZ), 773 $\mathrm{mg} \mathrm{L}^{-1}$ (CRAIZ) e $825 \mathrm{mg} \mathrm{L}^{-1}$ (IR). Outras espécies também necessitam da aplicação de IBA para induzir seu enraizamento, como é o caso de Sapium grandulatum, a qual apresentou diferenças significativas entre os tratamentos com IBA e a testemunha (Ferreira et al., 2001).

Durante as avaliações, não foi observada a formação de brotações de maneira expressiva nas estacas de alecrim-pimenta. Lopes et al. (2001) relataram que uma breve indução com auxina pode propiciar uma menor formação de calos e brotações, pois ainda os níveis endógenos da auxina permanecem baixos. Contudo, Erig et al. (2002) observaram um comportamento linear entre a concentração de IBA e o número de brotações em amoreira-preta, o que não foi observado neste trabalho.

A variável IR, cuja determinação é bastante

TABELA 1. Resumo da análise de variância para as variáveis: número de raízes (NRAIZ), número de brotações (BROTA), comprimento da maior raiz (CRAIZ), índice de enraizamento (IR) e porcentagem de enraizamento (PORC), avaliadas emestacas de alecrim-pimenta (Lippia sidoides) utilizando diferentes concentrações de ácido indollbutírico (IBA).

\begin{tabular}{l|c|c|c|c|cr}
\hline \multirow{2}{*}{ Fontes de variação } & \multirow{2}{*}{ Graus de liberdade } & \multicolumn{5}{|c}{ Quadrados médios } \\
& & NRAIZ $^{1}$ & BROTA $^{1}$ & CRAIZ & IR $^{1}$ & PORC \\
\hline C de AlB & 4 & $12,60^{\star \star}$ & 0,043 & $494,9^{* *}$ & $0,37^{\star \star}$ & 0,15 \\
Residuo & 20 & 0,59 & 0,033 & 62,78 & 0,42 & $0,07 \AA$ \\
\multicolumn{2}{l|}{ Coeficiente de Variação (\%) } & 19,47 & 15,32 & 35,5 & 14,3 & $29,1 \Xi$
\end{tabular}

** Significativo a $1 \%$ de probabilidade pelo teste $\mathrm{F}{ }^{1}$ dados transformados pari $\sqrt{X+0,5} 2$ dados transformados para arco 


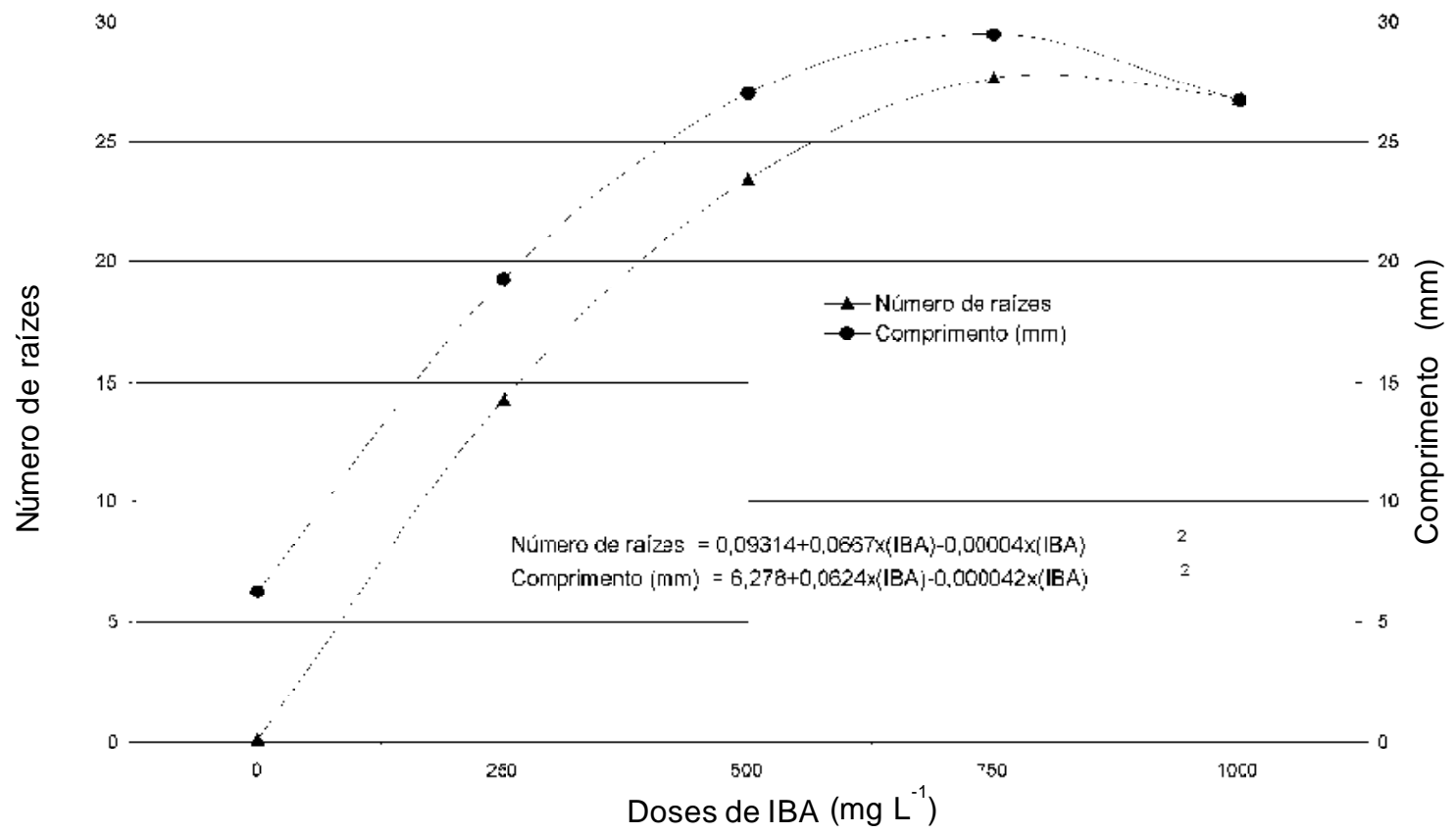

FIGURA 1. Número e comprimento de raízes em estacas do alecrim-pimenta (Lippia sidoides Cham.) submetidas a cinco níveis de ácido indolbutírico.

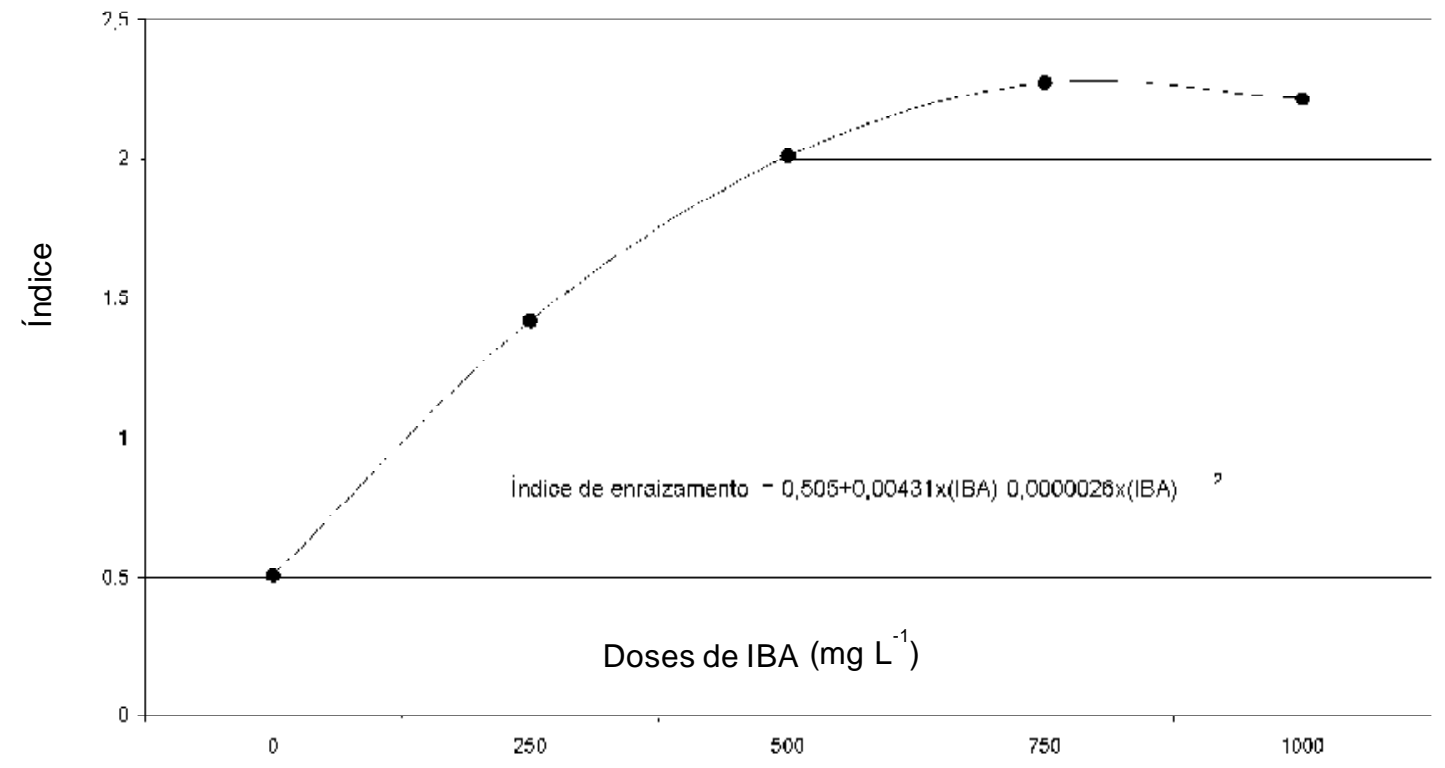

FIGURA 2. Índice de enraizamento em estacas do alecrim-pimenta (Lippia sidoides Cham.) submetidas a cinco níveis de ácido indolbutírico.

simples, mas subjetiva, apresentou alta correlação de Spearman com NRAIZ $(r=0,86, p<0,01)$, PORC $(r=0,97, p<0,01)$ e CRAIZ $(r=0,84, p<0,01)$, podendo ser utilizada com eficiência e rapidez para determinar tratamentos que permitem o melhor enraizamento.

A porcentagem de enraizamento não foi afetada significativamente, possivelmente pelo controle de umidade relativa e, também, pela manutenção de folhas nas estacas, as quais contribuíram para a produção de fotoassimilados e auxinas (Hartmann et al., 1990). Pimenta et al. (2007) observaram baixa capacidade de enraizamento em estacas das espécies não domesticadas de Lippia, mesmo com o uso do IBA. No mesmo estudo, Pimenta et al. (2007) observaram o efeito significativo do IBA sobre o número de raízes da espécie $L$. alba, não afetando a porcentagem de estacas enraizadas. Também em Lippia alba, as estacas medianas com 
quatro folhas foram as que apresentaram o maior desenvolvimento radicial, ao contrário das estacas sem folhas (Biasi \& Costa, 2003). Em alfavaca-cravo (Ocimum gratissimum), as mais altas porcentagens de enraizamentos ocorreram nas estacas medianas sem folhas e nas apicais com folhas (Ehlert et al., 2004). Emmaracujazeiro amarelo (Passiflora edulis), mantendo-se a metade da folha superior na miniestaca herbácea, o número médio de raízes emitidas aumentou de 13,21 para 19,51, representando um acréscimo de 47,7\% (Carvalho et al., 2007).

Assim, no enraizamento de estacas de alecrim-pimenta com folhas, em leito de enraizamento com umidade controlada, não há a necessidade do uso do IBA para elevar a porcentagem de germinação, sendo que tal regulador de crescimento apenas melhorou a qualidade das estacas enraizadas (NRAIZ e CRAIZ).

\section{REFERÊNCIA}

BIASI, L.A.; COSTA, G. Propagação vegetativade Lippia alba. Ciência Rural, v.33, n.3, p.455-9, 2003.

CARVALHO, R.I.; SILVA, I.D.; FAQUIM, R. Enraizamento de miniestacas herbáceas de maracujazeiro amarelo. Semina: Ciências Agrárias, v.28, n.3, p.387-92, 2007.
EHLERT, P.A.D.; LUZ, J.M.Q.; INNECCO, R. Propagação vegetativa da alfavaca-cravo utilizando diferentes tipos de estacas e substratos. Horticultura Brasileira, v.22, n.1, p.10-3, 2004.

ERIG,A.C.; ROSSI,A.;FORTES, G.R.L. 6-Benzilaminopurina e ácido indolbutírico na multiplicação da amoreira-preta (Rubis idaens L.) cv tupy. Ciência Rural, v.32, n.5, p.76570, 2002.

FERREIRA, B.G.A. et al. Enraizamento de Sapium glandulatum (Vell.) Pax. pela aplicação de ácido indol butírico e ácido bórico. Leandra, v.16, p.11-6, 2001.

HARTMANN, H.T. et al. Plant propagation: principles and practices. 5.ed. Englewood cliffs: Prentice Hall, 1990. $647 p$.

LOPES, S.C. et al. Enraizamento in vitro de mogno (Swietenia macrophylla King). Revista Cerne, v.7, n.1, p.124-8, 2001.

LORENZI, H.; MATOS, F.J.A. Plantas medicinais do Brasil: nativas e exóticas. Nova Odessa: Instituto Plantarum de Estudos da Flora, 2002. 512p.

ONO, E.O.; RODRIGUES, J.D. Aspectos da fisiologia do enraizamento de estacas caulinares. Jaboticabal: FUNEP, 1996. 83p.

PIMENTA, M.R. et al . Flowering, germination and rooting of cuttings of Lippia L. (Verbenaceae). Revista Brasileira de Botânica, v.30, n.2, p.211-20, 2007. 